\title{
INTERNACIONALIZAÇÃO DE ESTUDO: ESTRATÉGIA DE CLASSES MÉDIAS INTELECTUALIZADAS - CAMPO GRANDE/MS
}

\author{
Solange Bertozi de Souza ${ }^{1}$ \\ Jacira Helena do Valle Pereira Assis ${ }^{2}$
}

No presente artigo propomos uma discussão sobre a internacionalização de estudos como estratégia educacional de famílias de classes médias intelectualizadas - docentes universitários e filhos - na cidade de Campo Grande no estado de Mato Grosso do Sul, famílias essas que escolhem estabelecimentos de ensino bilíngues ou cursos livres de idiomas para seus filhos ou os enviam para estudos no exterior.

A intenção de se pesquisar as classes médias intelectualizadas, mais especificamente os professores universitários e suas famílias advém da necessidade de entender como essas famílias se organizam no sentido do processo de escolarização, se almejam uma formação intelectual para um mundo globalizado e atual, em busca de estratégias educacionais internacionais.

O número reduzido de estudos com esse enfoque, principalmente levando-se em consideração a realidade de Campo Grande e de Mato Grosso do Sul, confirmam a relevância deste estudo, que vai ao encontro das temáticas atuais no campo da Sociologia da Educação.

Apesar da redução de estudos nessa área, o mercado escolar campo-grandense no que se refere à internacionalização de estudos tem crescido. Há alguns anos temos monitorado a criação de escolas bilíngues e trilíngues em Campo Grande/MS. Em 2014, ao realizar um levantamento em sites de educação sobre a quantidade de escolas com ensino bilíngue e trilíngue, havíamos localizado apenas duas, ou apenas estas haviam divulgado seu trabalho na internet, quais sejam: a Escola Mon Petit, recém-inaugurada, e o Colégio Harmonia. Em 2015, esse número foi ampliado em mais três (Maple Bear Canadian School, Colégio Status, Escola SESC) e, no ano de 2016, surgiu mais uma escola, a Escola Kids@School. Em uma atualização no ano de 2018, foram localizadas outras cinco escolas: Escola Espaço Livre, Escola Viva Infância, Escola Gappe, O Quintal - Metropolitano MS, O Casulo - Instituto Ana Borges.

\footnotetext{
${ }^{1}$ Doutora em Educação pelo Programa de Educação da Universidade Federal de Mato Grosso do Sul (2019). Atua como docente da Universidade Católica Dom Bosco (UCDB) e Unigran Capital em Campo Grande - MShttp://orcid.org/0000-0003-4186-1002

${ }^{2}$ Doutora em Educação pela Universidade de São Paulo (2002). Atua como docente da Universidade Federal de Mato Grosso do Sul - https://orcid.org/0000-0002-4539-6462
} 
A internacionalização de estudos refere-se a duas faces de uma mesma moeda: a primeira está ligada à intenção de trazer o "estudo de fora do país" para dentro da realidade educacional brasileira, em que o ensino bilíngue ou trilíngue configura-se como um bom exemplo; a segunda diz respeito ao envio de jovens para o exterior, por meio de intercâmbios temporários ou para cursar o ensino médio, com o objetivo de propiciar o aprendizado do idioma e da cultura de outro povo. Em ambas, a discussão de fundo é o protagonismo que os estudos internacionais adquirem na formação de jovens na contemporaneidade.

Quando reflexionamos em como as classes médias intelectualizadas se organizam para a obtenção de estratégias educacionais, considerando que essas estratégias possibilitam o preparo acadêmico e profissional, é possível ter em mente que a busca pela internacionalização de estudo vem ao encontro da necessidade de manter relações com o mundo globalizado. Dessa forma, neste artigo trazemos à tona estas discussões, com a seguinte organização: primeiro, uma caracterização dos agentes da pesquisa e o lugar teórico das noções de internacionalização de estudos, classes médias intelectualizadas e estratégia educacional, em um segundo tópico, trazemos os relatos e análises dos agentes da pesquisa - famílias de docentes universitários que vivenciaram em suas famílias as propostas da internacionalização de estudos sob a forma de intercâmbio, escolas bilíngues e trilíngues, bem como de cursos livres de idiomas.

\section{OS AGENTES DA PESQUISA E AS NOÇÕES DE INTERNACIONALIZAÇÃO DE ESTUDOS, CLASSES MÉDIAS INTELECTUALIZADAS E ESTRATÉGIA EDUCACIONAL}

Inicialmente, apresentaremos a caracterização dos agentes da pesquisa desenvolvida com docentes universitários e seus filhos. Esse grupo é composto pelas famílias de classes médias intelectualizadas (pais e filhos - estudantes/graduados) foi constituído por 23 agentes, sendo que foram entrevistadas duas famílias de docentes cujos filhos realizaram o intercâmbio, oito famílias de docentes que colocaram seus filhos em cursos livres de idiomas e uma família cuja filha estudou em uma escola bilíngue.

Optamos por escolher as famílias dentre os docentes de universidades e faculdades públicas e privadas de Campo Grande, MS, por reunirem os requisitos para serem consideradas famílias de classes médias intelectualizadas. O critério de delimitação dos participantes no universo dessas famílias, foi selecionar aquelas que tivessem filhos(as) que realizam ou realizaram intercâmbio, que estudam ou estudaram em cursos livres de idiomas ou em uma escola bilíngue específica, escolhida por ser o estabelecimento de ensino bilíngue que está há mais tempo no mercado escolar campo- 
grandense e que trabalha com o ensino fundamental e médio. Dessa forma, a pesquisa foi delimitada dentro da cidade de Campo Grande, no estado de Mato Grosso do Sul.

TABELA 1 - AGENTES/PARTICIPANTES DA PESQUISA

\begin{tabular}{|l|l|}
\hline Famílias & Total de participantes \\
\hline Grupo do Intercâmbio & 04 \\
\hline Grupo dos Cursos Livres de Idiomas & 17 \\
\hline Grupo da Escola Bilíngue & 02 \\
\hline
\end{tabular}

Fonte: Pesquisa de campo, 2018. Organização: Autor, 2019.

As noções conceituais de internacionalização de estudos, classes médias intelectualizadas e estratégia educacional foram compreendidas com base na teoria de Pierre Bourdieu e seus interlocutores.

A internacionalização de estudos tem sido considerada pelos países em geral como sendo uma eficaz estratégia para se enfrentar o problema da concorrência mundial, tanto que, tornou-se uma tendência generalizada: "Durante a última década, a internacionalização tornou-se uma das mais importantes características da educação numa perspectiva quase mundial." (BROADY; BORJESSON; PALME, 2002, p. 206).

Com o mundo cada vez mais globalizado e com os meios de comunicação, as famílias começaram a se preocupar mais com o preparo de seus filhos para esse tipo de sociedade e, certamente, a internacionalização de estudos acaba sendo imperiosa para garantir que os herdeiros reproduzam suas posições de classe social.

No que tange à questão da estratégia, de acordo com Portes (1993, p. 17), o termo diz respeito ao "[...] conjunto de práticas e atitudes ideológicas ou morais que - consciente ou inconscientemente - cada grupo social põe em prática com uma determinada finalidade". Compreendemos que ao optar pelo investimento na internacionalização dos estudos, as famílias mobilizam estratégias que apresentam, em última análise, a formação intelectual e cultural internacional dos herdeiros como objetivo principal.

Ao relacionar a obtenção de capitais a estratégias vistas como investimentos educacionais, segundo Bourdieu (1996), as famílias tendem a transmitir seus capitais, e mais especificamente o capital cultural, utilizando-se, para tanto, de vários tipos de estratégias, e, dentre elas, as educativas. 
De acordo com Nogueira (2012, p. 117), os investimentos educacionais mobilizados pelas famílias de classes médias possuem algumas peculiaridades: "[...] a classe média viu aumentada sua capacidade estratégica, o que resultou numa sofisticação (isto é, diversificação) de seus investimentos educacionais. [...] Para as classes médias, o privilégio requer um trabalho contínuo e intenso.” Mas, por que concentrar a atenção em famílias de classes médias no que se refere às estratégias educacionais? Para a autora, isso se justifica,

Em parte, simplesmente porque elas constituem, a seu modo, um fenômeno contemporâneo maior. Elas merecem atenção porque existem. Porque são diversificadas [...] Mas, além disso, elas têm particular importância na sociologia da educação e na educação, porque suas ações produzem ou contribuem para a perpetuação, a inscrição e a reinvenção de velhas e novas iniquidades sociais. (NOGUEIRA, 2012, p. 111).

As classes médias não apresentam características homogeneizantes, mas, ao contrário, elementos diversificados, por ser multifacetada, torna-se uma tarefa árdua conceituá-la. Uma tentativa de conceituação foi realizada pelo Grupo de Trabalho para Definição de Nova Classe Média, da Secretaria de Assuntos Estratégicos, do Governo Federal, que partiu da seguinte premissa:

Embora não se possa definir com precisão o que é a classe média (dadas as múltiplas definições disponíveis), é razoável pensarmos que se trate de um grupo que varia em torno de um ponto que divide a população brasileira em duas, o que tecnicamente chamamos mediana da distribuição (50\% estão acima do ponto, e 50\%, abaixo desse ponto). Se estivermos falando da renda, estaremos falando do ponto em que $50 \%$ das pessoas terão uma renda menor e 50\% terão uma renda maior. No Brasil, a renda correspondente ao ponto do meio é de $\mathrm{R} \$ 440,00$ familiar per capita. Isso significa que 50\% dos brasileiros possuem renda familiar per capita inferior a $\mathrm{R} \$ 440,00$ e $50 \%$ possuem renda superior a R\$ 440,00 familiar per capita. (COMISSÃO PARA DEFINIÇÃO DA CLASSE MÉDIA NO BRASIL, 2012, p. 5).

Após essa definição de critérios, o Grupo fez a seguinte análise:

Dividimos a população brasileira em 100 pedaços de acordo com a renda domiciliar per capita. Colocamos os 100 pedaços na ordem da menor renda para maior renda (obtendo o que se chama tecnicamente de percentis da distribuição de renda). Verificamos quais os pontos de corte que dividem a população brasileira em 3 grupos (classe baixa, média e alta) de forma que o grau de vulnerabilidade seja o mais homogêneo possível do ponto de vista interno de cada grupo. O exercício estatístico resultou nos seguintes pontos de corte: $34^{\circ}$ e $82^{\circ}$ percentil. Assim, temos que a classe 
baixa termina no $34^{\circ}$, a classe média se situa entre o $34^{\circ}$ e o $82^{\circ}$ e a classe alta, do $82^{\circ}$ em diante. Em seguida, olhamos para a renda familiar per capita correspondente a esses percentis, chegando aos valores de R\$291,00 e R\$ 1.019,00. (COMISSÃO PARA DEFINIÇÃO DA CLASSE MÉDIA NO BRASIL, 2012, p. 6).

Dessa forma, são essas famílias que se situam em uma faixa de renda intermediária, ou seja, que não são consideradas famílias de baixa ou alta renda, assim, são famílias que precisam mobilizar e direcionar parte dos seus recursos financeiros para a concretização das estratégias que visam ao envio dos filhos a cursos em ambientes diversos do seu ambiente nativo, o que significa um investimento considerável e que causa impactos em seu orçamento familiar.

Nogueira (2010b) considera a configuração das classes médias um intento problemático e arbitrário, pois há diferentes perspectivas de análise que ocasionam conceituações por vezes adversas. As classes médias podem ser descritas como um arco que vai do polo mais material, em que são enfatizados o nível de rendimentos e o potencial de consumo, ao polo mais simbólico, que leva em consideração os modos de vida e visões de mundo desse grupo. Já os sociólogos focalizam a estrutura sócio ocupacional e o acesso a bens como educação, saúde, habitação, entre outros, como aspectos definidores da classe.

As mudanças que ocorrem dentro de uma classe social estão diretamente relacionadas à situação socioeconômica e política da sociedade e isso ocorreu no caso das classes médias, já que o desejo e o esforço de ascensão são evidenciados e parte desses esforços inclui aumentar o grau de escolaridade e diversificar as oportunidades profissionais para as novas gerações.

Essas transformações pelas quais passam as classes médias refletiram-se, consequentemente, na área da Educação, pois é nas classes médias, mais ainda do que nas classes superiores, que o processo de escolarização está fortemente integrado a uma estratégia de reprodução social. Nesse sentido, as famílias das classes médias se utilizam de várias estratégias educacionais, a fim de conseguir a preparação acadêmica e profissional de seus filhos, sendo que uma dessas estratégias é a internacionalização de estudos.

Adentrando mais especificamente a discussão sobre as classes médias intelectualizadas, que na teoria bourdieusiana é conceituada a partir de uma maior aproximação ao polo cultural, apontamos como características marcantes a disposição a um capital ligado às relações sociais e uma determinada familiaridade com a cultura e um "bom gosto" legitimados pela sociedade. Essas características possibilitam uma ligação maior com as práticas culturais da elite e é isso que as 
fazem ter uma distinção que ressalta sua necessidade de se diferenciar dos comportamentos das classes populares e também daqueles das frações mais tradicionais dos grupos das elites.

Dessa forma, neste artigo, utilizamos o enfoque que a teoria bourdieusiana tem sobre as classes médias intelectualizadas, focalizando que sua discussão se relaciona com a possibilidade de ser uma fração das classes médias na qual a ampliação do capital cultural está presente e, por isso, sua aproximação com a estratégia da internacionalização de estudos.

\section{INTERNACIONALIZAÇÃO DE ESTUDOS E ESTRATÉGIAS FAMILIARES DE CLASSES MÉDIAS INTELECTUALIZADAS: INTERCÂMBIO, ESCOLAS BILÍNGUES E TRILÍNGUES E CURSOS LIVRES DE IDIOMAS.}

Partimos do entendimento que a utilização da internacionalização de estudos apresenta-se como uma estratégia educacional de famílias de classes médias intelectualizadas a fim de possibilitar um maior trânsito no mundo globalizado contemporâneo. Assim, as classes médias, vêm intensificando cada vez mais suas estratégias educativas para tirar proveito dos recursos culturais e econômicos de que são detentoras, favorecendo a escolaridade de seus filhos com o intuito de assegurar a reprodução ou a ascensão na escala social.

Apresentamos a seguir os tipos de proposta de internacionalização de estudos, vivenciados pelos agentes da pesquisa, tanto os que se encontram dentro do cenário brasileiro, quanto o que é realizado no exterior.

\subsection{Intercâmbio: uma proposta de internacionalização de estudos no exterior}

O primeiro movimento de internacionalização que apresentamos é o intercâmbio, que se configura como uma estratégia educacional utilizada pelas classes médias intelectualizadas, pois agrega uma dupla finalidade: auxiliar o rendimento intelectual e escolar de seus filhos e também o processo de autonomia pessoal, consequentemente, apresenta-se como uma das estratégias para a reprodução do patrimônio cultural e social da família.

O intercâmbio é um fenômeno fortemente presente no século XXI e é considerado uma prática que tem crescido de forma significativa no Brasil, apesar de já existir referência a esse movimento de internacionalização no passado. (FRANÇA, 2008).

Tamião e Cavenaghi (2013) observam que o intercâmbio nasceu ligado diretamente à ampliação do relacionamento entre povos e culturas. Apesar de ser uma prática de deslocamento muito antiga, hoje esse tipo específico de viagem é desenvolvido em busca do conhecimento de 
novas línguas e ainda pela necessidade de aprendizado de outro modelo cultural de comportamento, por meio da internacionalização.

O período de estudos fora do país significa, portanto, para muitas famílias um fator imprescindível na busca de ampliação do capital cultural. Uma das vantagens que levam à escolha desse tipo de estratégia está ligada à possibilidade de, após o intercâmbio, o estudante obter um melhor desempenho no processo de seleção para ingresso no curso em nível superior, cujo contato com outras culturas é importante para se conseguir melhores resultados.

Outra vantagem é que a realização de intercâmbios pode, ainda, tornar o jovem estudante mais flexível no que se refere à aceitação da opinião de outras pessoas, pois, ao ter contato com outras referências culturais, aguça-se o respeito a pontos de vista e perspectivas diferentes, conforme o pertencimento cultural de cada um. Essa característica mostra-se desejável ao perfil do profissional requisitado pelos altos cargos no mercado de trabalho, justificando o interesse das classes médias nesse investimento, que conferiria aos seus herdeiros maiores possibilidades de sucesso na carreira profissional.

Os intercâmbios são considerados pelas famílias como uma estratégia utilitarista para se conseguir sucesso escolar, contudo as famílias que fazem uso dessa prática também acreditam proporcionar aos seus filhos bem-estar psicológico e realização pessoal, visto que eles adquirem experiências diferenciadas ao conviver com outra cultura.

No entanto, dentre todos os fatores mobilizadores, o aprendizado de outra língua tem se mostrado um elemento essencial. De fato, segundo Nogueira e Nogueira (2009, p. 35), o “[...] domínio da língua culta funciona como uma moeda (um capital) que propicia a quem o possui uma série de recompensas, seja no sistema escolar, seja no mercado de trabalho, seja até mesmo no mercado matrimonial."

No relato de uma das mães do jovem que fez intercâmbio é evidenciado o fato de acreditar que a utilização da internacionalização de estudos proporciona vantagens e consequentemente reforça o sonho de futuro melhor para o filho: "O intercâmbio ajudou muito meu filho na hora de se preparar para o vestibular.” (SILVIA/DOCENTE/INTERCÂMBIO). Para Silvia, a utilização dessa estratégia possibilitou ao filho facilidades no processo de escolarização logo após a ida para o intercâmbio e proporcionou-lhe a realização pessoal por conseguir alcançar sua meta, que era prestar vestibular. Nessa situação, o intercâmbio foi realizado antes do vestibular e vinculado pela mãe à aprovação do filho no referido processo seletivo. 
Há uma relação estreita entre esforços, estratégias e investimentos, pois é interessante associar as estratégias empreendidas pela família com as expectativas e investimentos. No relato a seguir ficam evidenciados os esforços pessoais que a docente empenhou para que sua filha, que fez intercâmbio, usufruísse da estratégia da internacionalização de estudos: "Tenho mais condições financeiras do que meus pais para fazer isso e hoje existe mais acessibilidade para fazer os investimentos. Meus pais eram semianalfabetos com dez filhos e financeiramente prejudicados." (ELISA/DOCENTE/INTERCÂMBIO).

Elisa faz uma comparação entre sua condição financeira atual com a condição de seus pais, sinalizando as dificuldades que eles tinham até mesmo para investir nos estudos dela e de seus irmãos e assinala a facilidade que possui hoje para fazer investimentos educacionais, já que há uma acessibilidade maior para isso.

Ainda no que diz respeito ao intercâmbio, não podemos deixar de abordar sobre o Programa Ciência sem Fronteiras, que busca promover a consolidação, expansão e internacionalização da ciência e tecnologia, da inovação e da competitividade brasileira por meio do intercâmbio e da mobilidade internacional. Esse programa surgiu no ano de 2011, como proposta conjunta dos Ministérios da Ciência, Tecnologia e Inovação (MCTI) e do Ministério da Educação (MEC), por meio de suas respectivas instituições de fomento - CNPq e Capes -, e Secretarias de Ensino Superior e de Ensino Tecnológico do MEC. (MANÇOS; COELHO, 2017).

O programa visa promover intercâmbio entre os alunos de graduação e pós-graduação (depois de 2017 somente participam alunos de pós-graduação), por meio de estágio no exterior, com o intuito de propiciar contato com diferentes sistemas educacionais relacionados à tecnologia e inovação. Outro objetivo é motivar pesquisadores internacionais, que almejam se fixar no Brasil, a firmar parcerias com pesquisadores brasileiros nas áreas específicas do programa e ainda oportunizar aos pesquisadores de empresas treinamento especializado no exterior.

Uma das prioridades do programa é proporcionar a mobilidade acadêmica internacional de estudantes, professores e pesquisadores, sendo essa uma maneira de desenvolver estudos, treinamentos e pesquisas em instituições no exterior. Vários países já possuem programas de cooperação internacional, buscando a mobilidade acadêmica e esta é uma das atividades que mais se destacam no processo de internacionalização, por isso sua efetivação.

Dessa forma, podemos constatar que a proposta do Programa Ciência sem Fronteiras vem ao encontro das necessidades contemporâneas relativas à abertura ao mundo globalizado e à expansão das fronteiras. A conclusão a que chegamos é que o Brasil precisa expandir sua perspectiva de 
abertura à globalização como também proporcionar um processo de interação maior com outros países, já que esta tem sido uma característica mundial.

Contudo, observamos que as áreas priorizadas pelo programa estão relacionadas à engenharia e áreas tecnológicas, indústria farmacêutica, sociedade da informação, cultura de massa, ou seja, áreas intrinsecamente relacionadas ao mercado, atendendo também ao interesse do capital não se vê, por exemplo, priorização da área de educação. Outro aspecto a ser apontado é o encerramento das bolsas de graduação e a vinculação das pós-graduações a pesquisas particularmente voltadas à indústria. Mas, em resumo o Programa Ciência sem Fronteiras é algo que demanda movimento da sociedade para que se recupere suas linhas mestras e produza intercâmbio para estudantes de todas as classes sociais.

\section{Escolas bilíngues e trilíngues: uma proposta de internacionalização de estudos dentro do Brasil}

No cenário escolar nacional - educação básica a cada dia vem crescendo as escolas bilíngues e trilíngues. A ideia de escola bilíngue segundo Harmers e Blanc (2000, p.189) é compreendida como "[...] qualquer sistema de educação escolar no qual, em um dado momento e período, simultânea ou consecutivamente, a instrução é planejada e ministrada em pelo menos duas línguas."

A possibilidade de estudar uma língua diferente da sua com vistas à proficiência e não somente para a obtenção de conhecimentos rudimentares, como o que se observa nas escolas públicas brasileiras, proporciona ao jovem estudante uma melhoria nos relacionamentos sociais e profissionais, bem como um maior desenvolvimento cultural e intelectual. Dessa forma, é observado que esta tem sido uma estratégia utilizada por alguns estabelecimentos de ensino, especialmente os privados, que buscam proporcionar um diferencial a sua clientela, por meio do ensino bilíngue.

Em decorrência disso, há famílias de algumas frações das classes médias que se utilizam da escolha do estabelecimento internacional para seus filhos, em níveis de ensino fundamental e médio, preterindo o ensino nacional, pois é na opção internacional que as famílias buscam alternativas diferenciadas das encontradas no nacional. (PRADO, 2002).

Há também outra questão: em busca de maior diferenciação no mercado, alguns estabelecimentos estão proporcionando não somente o ensino de uma língua estrangeira, mas também de uma segunda língua, que é o caso das escolas trilíngues. Nesse caso, é importante observar se realmente os conteúdos curriculares estão sendo ministrados nas três línguas ou se é apenas uma questão de marketing da escola. 
Observamos que tem crescido o número de escolas, tanto no exterior como no Brasil, que tem se utilizado desse tipo de estratégia para atrair mais estudantes, ainda que nem sempre a preocupação seja, efetivamente, com o aprendizado, essa é uma situação encontrada também em Campo Grande, MS, além de em outras cidades brasileiras.

A escolha de um ensino internacional constitui-se em uma das estratégias educativas que têm como objetivo implementar a manutenção ou o desenvolvimento de um capital internacional já acumulado, sendo que o domínio de uma língua estrangeira propicia maior facilidade para se conviver em meio internacional.

Marcelino (2009) assegura que a escola bilíngue é considerada uma escola brasileira, com a diferença de que os conteúdos e interações escolares ocorram também em outro idioma. Dentro desse ambiente, a criança se desenvolve, age e interage com o meio e ainda adquire e constrói conhecimento. Com a possibilidade de colocar seu filho em uma escola bilíngue ou trilíngue, os pais reflexionam obter uma educação que esteja em consonância com as exigências do mundo do trabalho.

No relato da docente que colocou sua filha para estudar em uma escola bilíngue, a relatividade da autonomia da jovem ficou aparente quando a mãe demonstrou seu propósito de preparar sua filha para o mundo do trabalho: "Eu desejo que depois da formatura, possa conseguir uma boa colocação no mercado, mas que continue estudando para o resto da vida." (HELENA/DOCENTE/ESCOLA BILÍNGUE).

Helena almeja que sua filha Gisele consiga efetivar sua participação no mundo do trabalho, todavia também assinala que a filha necessita estudar a vida inteira. Esse é o posicionamento que a mãe tem sobre a maneira de lidar com o mundo do trabalho e ela reforça sua opinião no questionamento sobre a diferença entre as expectativas escolares e profissionais de seus pais para com ela e aquelas que têm hoje para com sua filha: "Existe uma diferença nas expectativas hoje há exigência de maior formação profissional." (HELENA/DOCENTE/ESCOLA BILINGUE). Além da valorização familiar no investimento educacional, Helena justifica sua maneira de perceber o mundo do trabalho alegando que, na atualidade, a cobrança por uma formação profissional é maior do que em tempos anteriores, sendo assim acredita que sua filha precisa estudar mais.

Ainda em relação à questão da proposta da escola bilíngue, segundo Salgado e Dias (2010, p. 149), a preocupação desse tipo de escola precisa ser o de "[...] desenvolver no aprendiz suas condições individuais de uso das línguas que se dispõem em seu repertório.” Isto significa que, ao ensinar em uma segunda língua, a escola não deve suprimir uma para dar lugar à outra, pois em 
ambientes informais (casa do estudante, por exemplo) a utilização da sua língua materna se fará necessária.

Nesse sentido, Salgado e Dias (2010) enfatizam que cabe à escola não apenas ensinar uma segunda língua ou mais de uma, mas ensinar ao estudante a importância de respeitar a diversidade e de aceitar a vivência em relação às questões interculturais. Um aspecto relevante na relação com a educação bilíngue é o fato de a pessoa formada em escola bilíngue brasileira ter algum nível de proficiência nas quatro habilidades: ler, escrever, ouvir, falar; embora seja presumível que ela possa se sobressair mais em uma ou outra habilidade, dependendo de aptidão, identificação e interesse, além de outros fatores que possam influenciar no aprendizado.

Em síntese, observamos que os estabelecimentos de ensino que preparam os jovens para uma perspectiva internacional, como as escolas bilíngues e trilíngues, vão ao encontro da expectativa de famílias de classes médias que optam por investir na estratégia da internacionalização dos estudos, visando propiciar aos seus filhos um diferencial e maiores chances de obter preparo escolar e profissional.

\subsection{Cursos livres de idiomas: uma proposta de internacionalização de estudos dentro do Brasil}

Os cursos livres de idiomas são considerados um tipo de internacionalização de estudos desenvolvidos dentro do país. Os referidos cursos são vistos como um espaço eficiente de aprendizagem de idiomas, já que os estudantes têm tempo suficiente de exposição ao insumo da língua, as salas de aula são menores, as turmas são mais homogêneas, com infraestrutura adequada e os professores são capacitados e bem remunerados. (ASSIS-PETERSON; COX, 2007).

Marcelino (2009) menciona que os cursos livres de idiomas têm como objetivo principal ensinar a língua e favorecer o desenvolvimento linguístico com um número determinado de dias e horas para o conteúdo ser ministrado, nos quais o estudante é testado com frequência para avaliação da fixação das estruturas.

Entretanto, uma questão relacionada aos cursos livres de idiomas precisa ser dimensionada, isto é, o fato de que nem sempre apresentarem padrão de excelência no ensino, pois como não existe uma supervisão direta das autoridades educacionais, alguns acabam lesando o estudantecliente com propagandas enganosas ao proporem um ensino de qualidade que, na prática, não ocorre. Assis-Peterson e Cox (2007), em relação a essa falta de interesse das autoridades educacionais, indicam que:

[...] o governo, em suas várias instâncias, parece estar conformado com a profecia de que só se aprende inglês na escola de idiomas, legitimando a demarcação de 
competências. Só aprende inglês quem pode pagar pelas aulas nos cursos livres. Quer dizer, só terá esse capital cultural quem puder comprá-lo. Essa é a ordem natural das coisas numa sociedade capitalista, e, essa crença, embora não assumida explicitamente, é apoiada implicitamente pela inércia em mudar seu status de incompetente. (ASSIS-PETERSON; COX, 2007, p. 12).

Vemos então o problema da desigualdade social, isto é, as pessoas que não podem pagar por esse ensino adicional, por não terem condições financeiras para tal, não se tornam aptas a competir igualmente no mundo do trabalho em alguns postos e cargos que exijam tal complementação da formação ou ofereçam oportunidade de trabalho em país estrangeiro. O peso disso está em que, em várias profissões, altos salários são pagos por multinacionais ou transnacionais e estas vagas, embora para poucos, são almejadas tanto por pessoas advindas de classes baixas quanto por filhos das classes altas, que assim, conseguem manter seu status financeiro.

Porém, no que se refere às opiniões das pessoas que podem ou puderam usufruir do estudo em curso de línguas, em alguns relatos dos agentes da pesquisa a crença nos benefícios na área escolar decorrentes do uso da internacionalização de estudos, esteve presente:

\section{Até o momento estou colhendo os frutos de ter estudado línguas. (CLAUDIA/JOVEM/CURSO LIVRE DE IDIOMAS).}

O curso de língua estrangeira me permitiu mais preparo nos estudos, pois ganhei bolsa de estudo para estudar em uma escola particular devido ao meu desempenho. (EVELIN/JOVEM/CURSO LIVRE DE IDIOMAS).

O curso de línguas me deixou mais preparado para os estudos porque, de alguma forma, contribuiu para concluir o ensino médio. (JOÃO/JOVEM/CURSO LIVRE DE IDIOMAS).

Tanto Claudia, quanto Evelin e João sentiram os reflexos dos estudos de línguas que realizaram logo depois de o terem feito e atribuem algumas vantagens que obtiveram ao fato de terem escolhido realizar essa estratégia educacional. Os benefícios elencados pelos referidos agentes dizem respeito à possibilidade da continuidade da trajetória de escolarização, dando à Evelin uma bolsa de estudo em uma escolar particular e para João, a conclusão do ensino médio.

João acredita que o aprendizado de outro idioma o ajudou na conclusão do ensino médio, enquanto Claudia acredita ter colhido "frutos" de forma vaga, sem especificar os benefícios obtidos. O caso específico de Evelin traz de volta a discussão sobre o custo das escolas mais renomadas, preparatórias para os vestibulares e seu acesso. A dedicação ao idioma estrangeiro significou, na 
prática, uma vaga numa escola a que ela talvez não tivesse acesso caso necessitasse pagar integralmente por isso.

Dessa forma, as estratégias educacionais empreendidas pelas famílias de Claudia, Evelin e João são mobilizadas para que ocorra o movimento de transmissão dos capitais, principalmente o capital cultural. Reforçando a questão da relação entre família, estratégias e capitais, a teoria bourdieusiana focaliza o papel que a família possui ao transmitir seus capitais e, mais especificamente, o capital cultural. Esse movimento de transmissão envolve a mobilização de vários tipos de estratégias, dentre elas as educativas, as quais se referem ao investimento realizado pelos pais para encaminhar os filhos para escolas e cursos considerados "ideais", na ótica da legitimação da classe social pertencente.

No relato de uma docente cuja filha fez curso livre de línguas, a reprodução das estratégias (no caso, educacionais) para os descendentes aparece evidenciada: "Meus pais deram estudo para mim e hoje tenho mais condições financeiras que eles, por isso espero que minha filha faça uma faculdade no qual se identifique.” (CÉLIA/DOCENTE/CURSO LIVRE DE IDIOMAS). Célia teve a oportunidade de estudar porque seus pais propiciaram isso a ela e, em contrapartida, acha importante dar essa possibilidade para sua filha, sendo a utilização da internacionalização de estudos por meio do curso de línguas um dos reflexos desse investimento.

No relato de outra docente que optou por um curso de línguas como investimento educacional para sua filha, outra condição familiar também apareceu: "Minha filha terá um estudo no qual vai auxiliá-la para futuros estudos, intercâmbios, etc., pois antes meus pais não tinham tantas condições e eu hoje posso dar para minha filha uma vida melhor." (ANITA/DOCENTE/CURSO LIVRE DE IDIOMAS).

Anita relatou que seus pais não tiveram condições de investir em seus estudos, mas que ela fez isso com sua filha, portanto, a referida docente percebe a diferença entre a condição financeira de seus pais e a condição que ela possui atualmente, acreditando que por meio dos estudos, poderá proporcionar uma vida melhor para a sua filha Evelin.

Os sonhos e anseios em proporcionar condições melhores para seus filhos no que se refere ao processo de escolarização foi algo recorrente nas entrevistas das famílias que participaram da pesquisa, reforçando a concepção de que a utilização de estratégias educacionais é importante nesse processo. 


\section{À GUISA DE CONSIDERAÇÕES FINAIS}

Este artigo visou lançar luz sobre a internacionalização de estudos utilizada como estratégia educacional de famílias de classes médias intelectualizadas, neste caso caracterizadas e compreendidas como docentes da educação superior e seus filhos. Refletimos sobre até que ponto as estratégias de internacionalização de estudos atingem o mundo internacional, particularmente o mundo do trabalho e se o preparo acadêmico e profissional, ou seja, a ampliação do volume do capital cultural que esses professores almejam e fornecem aos seus filhos, de fato os leva à internacionalização.

Realizamos aproximações, por meio dos relatos obtidos que nos indicaram que a preparação para os diferentes universos - internacional, nacional e regional - acontece quando as famílias empreendem estratégias, fazendo investimentos financeiros e escolares para atingir tal objetivo, sendo que muitas vezes elas procuram o que consideram o ideal, que no caso é uma formação que se considera internacionalizada.

É relevante salientar que este ideal construído vem pautado na compreensão ainda que superficial do contexto da globalização e não atinge toda a sociedade, mas partes dela, neste caso específico pais professores universitários, considerados de classes médias e intelectualizados.

Segundo os relatos dos pais e dos filhos agentes da pesquisa, é possível sinalizar que esses elencam benefícios da utilização da internacionalização de estudos, embora isso ocorra em alguns casos com uma concepção romantizada do que seria se utilizar da internacionalização de estudos.

Em comum os pais entrevistados acreditam que as oportunidades de estudos permitidas aos filhos terão influência em sua colocação no mercado de trabalho. Trata-se, entretanto, de um mercado mais especializado, com melhores salários e planos de carreira, o que eles esperam é que esses filhos acessem oportunidades de trabalho que remunerem bem melhor que a média do país. Todo esse esforço é motivado pelo desejo de ascensão cultural, intelectual, simbólico e econômico.

É preciso compreender a internacionalização enquanto um movimento que pode visar ao aprendizado de uma língua estrangeira e/ou o intercâmbio cultural ou escolar propriamente, se pensarmos especificamente nos estudos. Caberia observar ainda que a internacionalização de estudos pretende adaptar um sujeito de uma dada cultura a relacionar-se com outra em aspectos globais, por exemplo, cursando o ensino médio ou ensino superior em outro país que não o seu de origem, ou ainda, em seu país, mas com um aprendizado que permita a ele trabalhar em outro futuramente. Grosso modo, o conhecimento de outra cultura incluindo seus aspectos econômicos, já 
que um dos interesses por esse tipo de estudo é propiciar oportunidades de trabalho no mundo do trabalho internacional.

A desigualdade social também aparece na situação de internacionalização de estudos, cuja realidade consiste no fato de que quem possui condições de fazer investimento nessa área pode se beneficiar da rentabilidade do capital internacional ao longo da trajetória escolar, em detrimento daqueles que estão em uma situação com menos privilégios, limitados aos recursos nacionais, a menos que se utilizem do recurso de programas de intercâmbio proporcionados pelo governo brasileiro, como é o caso do Programa Ciência sem Fronteiras.

Em síntese, a internacionalização de estudos, neste artigo, foi considerada uma estratégia educacional por parte de professores universitários e seus filhos em Campo Grande - Mato Grosso do Sul, os quais buscam adesão ao mundo globalizado, indo além das fronteiras nacionais. As famílias investigadas possuem a propensão de investir no estudo das línguas estrangeiras e isso ocorre porque percebem os ganhos e vantagens que esse investimento pode trazer aos seus filhos, todavia, essa é uma prerrogativa de grupos restritos. 


\section{REFERÊNCIAS}

ASSIS-PETERSON, A. A.; COX, M. I. P. Inglês em tempos de globalização: para além de bem e mal. Calidoscópio, São Leopoldo, v. 5, n. 1, p. 5-14, jan./abr. 2007.

BOURDIEU, P. Razões Práticas: sobre a teoria da ação. Tradução Mariza Corrêa. Campinas: Papirus, 1996.

BRASIL. Secretaria de Assuntos Estratégicos. Comissão para definição da classe média no brasil. Relatório sobre a definição da classe média no Brasil. Brasília: Secretaria de Assuntos Estratégicos, 2012.

BROADY, D.; BORJESSON, M.; PALME, M. Go West! O sistema de ensino sueco e os mercados transnacionais. In: ALMEIDA, A.M.F.; NOGUEIRA, M.A. (Org.). A escolarização das elites: um panorama internacional da pesquisa. 2.ed. Petrópolis: Vozes, 2002. p. 192-222.

FRANÇA, M. C. C. C. Cidadãos do mundo: experiências pessoais e familiares entre participantes de um Programa de Intercâmbio Cultural. Mouseion, [s.1], v. 2, n. 3, p. 1-15, jan./jun. 2008.

HARMERS, J.: BLANC. M. Bilinguality and Bilingualism. Cambridge: Cambridge University Press, 2000.

MANÇOS, G.R.; COELHO, F.S. Internacionalização da Ciência Brasileira: subsídios para avaliação do programa Ciência sem Fronteiras. Revista Brasileira de Políticas Públicas e Internacionais, v.2, n.2, p. 52-82, dez. 2017.

MARCELINO, M. Bilinguismo no Brasil: significado e expectativas. Revista Intercâmbio, São Paulo, v. XIX, p. 1-22, 2009.

NOGUEIRA, M.A. Classes médias e escola: novas perspectivas de análise. Currículo sem fronteiras, Pelotas, v.10, n.1, p. 213-231, jan./jun. 2010b.

. Um tema revisitado - as classes médias e a educação escolar. In: DAYRELL, J. et al. (Org.). Família, escola e juventude: olhares cruzados Brasil-Portugal. Belo Horizonte: Editora UFMG, 2012, p. 110-131.

NOGUEIRA, M.A.; NOGUEIRA, C.M.M. Bourdieu e a Educação. 3. ed. Belo Horizonte: Autêntica, 2009.

PORTES, E.A. Trajetórias e estratégias escolares do universitário das camadas populares. 1993. Dissertação (mestrado) - Faculdade de Educação. Universidade Federal de Minas Gerais, Belo Horizonte.

PRADO, C. L. Intercâmbios culturais como práticas educativas em famílias das camadas médias. Tese (Doutorado) - Universidade Federal de Minas Gerais, Belo Horizonte, 2002.

SALGADO, A.C.P.; DIAS, F.H. Desenvolver a bilingualidade: foco da educação bilíngue e do ensino de línguas. Signo. Santa Cruz do Sul, v. 35 n. especial, p. 145-153, jul./dez. 2010.

TAMIÃO, T. S.; CAVENAGHI, A. J. O Intercâmbio Cultural Estudantil na Cidade de São Paulo. Revista do Instituto de Ciências Humanas, Belo Horizonte, v. 8, n. 9, p. 40-49, jan./jun. 2013. 


\section{RESUMO}

Este artigo trata da internacionalização de estudos usada como estratégia educacional de famílias de classes médias intelectualizadas de Campo Grande-MS. O objetivo é compreender se essas famílias buscam uma formação intelectual internacional. A teoria remete a Bourdieu e interlocutores, foi feita revisão bibliográfica, aplicação de entrevistas semiestruturadas com docentes universitários e seus filhos, que fizeram intercâmbio internacional, estudaram em escola bilíngue ou em cursos livres de línguas. Os resultados mostraram que a internacionalização de estudos é considerada uma estratégia educacional e na análise identificou-se que ela traz vantagens a quem pode ter acesso o maior desafio é fazer com que possa ser utilizada por toda a população brasileira, sem que haja distinções.

Palavras-chave: Internacionalização de estudos. Famílias de classes médias intelectualizadas. Mundo globalizado.

\section{STUDY INTERNATIONALIZATION: STRATEGY OF INTELLECTUALIZED MIDDLE CLASSES - CAMPO GRANDE/MS}

\section{ABSTRACT}

This article deals with the internationalization of studies used as an educational strategy for intellectualized middle classes families in Campo Grande-MS. The aim is to understand if these families seek an international intellectual formation. The theory refers to Bourdieu, a bibliographical review was carried out, the application of semi-structured interviews with university professors and their children, who made international exchange, studied in bilingual school or in language-free courses. The results showed that the internationalization of studies is considered an educational strategy and in the analysis it was identified that it brings advantages to those who can have access, the biggest challenge is to make it be used by the entire Brazilian population.

Keywords: Internationalization of studies. Families of intellectualized middle classes. Globalized world.

\section{INTERNACIONALIZACIÓN DE ESTUDIO: ESTRATEGIA DE CLASES MEDIAS INTELECTUALIZADAS -CAMPO GRANDE/MS}

\section{RESUMEN}

Este artículo trata de la internacionalización de estudios usada como estrategia educativa de familias de clases medias intelectualizadas de Campo Grande-MS. El objetivo es comprender si esas familias buscan una formación internacional. La teoría remite a Bourdieu, se realizó una revisión bibliográfica, aplicación de entrevistas semiestructuradas con docentes universitarios y sus hijos, que hicieron intercambio internacional, estudiaron en escuela bilingüe 0 en cursos libres de lenguas. Los resultados mostraron que la internacionalización de estudios es considerada una estrategia educativa y en el análisis se identificó que ella trae ventajas a quien puede tener acceso, el mayor desafío es hacer que pueda ser utilizada por toda la población brasileña.

Palabras clave: Internacionalización de estudios. Familias de clases medias intelectuales. Mundo globalizado.

Submetido em 30 de março de 2019 Aprovado em 01 de setembro de 2019 